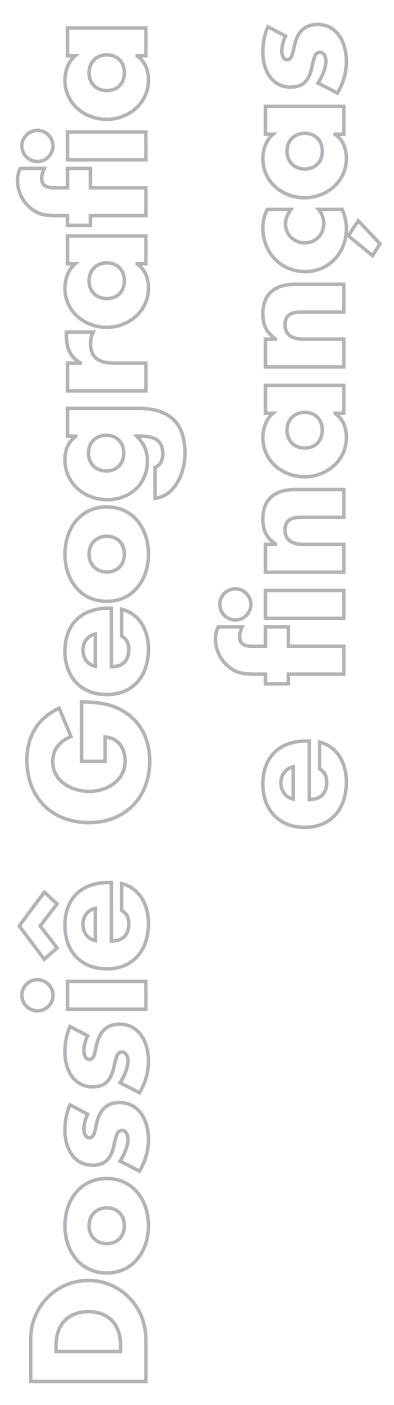

revista

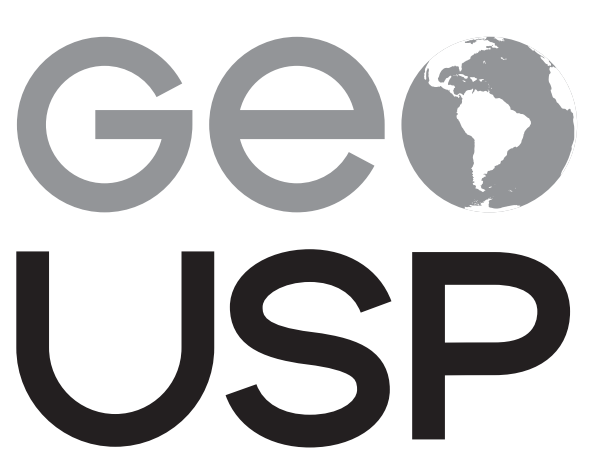

espaço e tempo

Volume $21 \cdot n^{\circ} 2$ (2017)

ISSN 2179-0892
Banalidade das finanças e cidadania incompleta: lugar e cotidiano na globalização

\author{
María Laura Silveira \\ UBA/Conicet
}

p. $370-383$

Como citar este artigo:

SILVEIRA, M. L. Banalidade das finanças e cidadania incompleta: lugar e cotidiano na globalização. Geousp - Espaço e Tempo (Online), v. 21, n. 2, p. 370-383, agosto. 2017. ISSN 2179-0892.

Disponível em: < http://www.revistas.usp.br/geousp/ article/view/135155>. doi: 10.11606/issn.2179-0892. geousp.2017.135155.

\section{(c) $(1) \Theta$}

Este artigo está licenciado sob a Creative Commons Attribution 4.0 License. 


\title{
Banalidade das finanças e cidadania incompleta: lugar e cotidiano na globalização
}

\section{Resumo}

Este artigo está estruturado em três pontos. No primeiro, procura entender o cotidiano como quinta dimensão do espaço banal e o papel da multiplicação dos fluxos financeiros, envolvendo um maior número de lugares. No segundo, discute a reorganização do cotidiano ao ritmo da financeirização que desenvolvem nos lugares os agentes do circuito superior, por meio de ações simbólicas e novos instrumentos financeiros. No terceiro ponto, aborda o papel do Estado na financeirização e no consumo e suas repercussões nos circuitos da economia urbana e na cidadania. Por fim, apresenta breves reflexões sobre a relação entre política, produção, consumo e cidadania no período atual.

Palavras-chave: Cotidiano. Finanças. Crédito. Cidadania. Circuitos da economia urbana.

\section{Banality of finance and incomplete citizenship: place and quotidian in globalization}

\begin{abstract}
This paper is organized in three points. First, we discuss quotidian as a fifth dimension of banal space and the multiplication of financial fluxes, involving many more places. Second, we seek to address how everyday life is reorganized through symbolic actions and new financial instruments of the upper circuit in every place. Third, we propose to understand the function of State by considering financialization and consumption and their effects in circuits of urban economy and citizenship. Finally, we reflect about the relationship among politics, production, consumption and citizenship in globalization period.
\end{abstract}

Keywords: Quotidian/everyday. Finance. Loan. Citizenship. Circuits of urban economy. 


\section{Espaço banal e cotidiano}

Por que parece haver uma defasagem entre, de um lado, a constituição e a difusão do consumo e, de outro, a consolidação e a expansão da cidadania? Ou quiçá o advento do consumo aproximar-nos-ia da tão almejada conquista da cidadania? Imaginar o consumo e a cidadania, lado a lado numa tensão teórica e política, será uma falsa questão?

Poderíamos iniciar essa discussão pela ideia, proposta por Milton Santos (1996a), de uma relação constitutiva entre cotidiano e espaço banal. ' Segundo Santos (1996a, p. 257), graças ao papel da informação e da comunicação na vida social, o cotidiano ganha hoje novas dimensões, sendo uma delas a espacial, mas ao mesmo tempo "esse cotidiano enriquecido se impõe como uma espécie de quinta dimensão do espaço banal".

Contudo, torna-se necessária uma breve questão preliminar sobre as dimensões do espaço. Não de um modo linear, a história da geografia tem mostrado ora o predomínio de visões de um espaço de duas dimensões, permitindo a formulação de propostas geométricas e topológicas, ora vertentes ancoradas na concepção de tempo como um continuum de Newton como as visões kantianas de um espaço tridimensional. Mais tarde, a teoria da relatividade com a noção de espaço-tempo quadridimensional permitiu desanuviar a questão da relação entre ambos. A partir desse momento, tempo e espaço já não são mais vistos como absolutos, mas como relativos. Nesse sentido, para Einstein não há um tempo cósmico presente em todo o universo, uma vez que "cada pedaço da matéria tem seu próprio tempo local" (Russell, 1983, p. 282). Nesta interpretação, o mundo não é mais percebido como uma multiplicidade de partículas em movimento, mas como uma multiplicidade quadridimensional de eventos.

Crítico da tradição disciplinar da geografia e empenhado num exercício renovado de teorização, Santos (1986) não foi indiferente à concepção de espaço-tempo de Einstein, a qual the permitiu reforçar a ideia de ver o espaço como um sistema de relações ou um campo de forças. Nessa conceituação do espaço o tempo é uma dimensão essencial e constitutiva. De tal modo, existe um tempo próprio do lugar e cada ponto no espaço permite uma percepção do tempo. Mais do que nunca antes podemos pensar o espaço como movimento. Lembremos que Armando Corrêa da Silva (1986) considerava necessário estudar o espaço a partir das dimensões absoluta, relativa e relacional do real e, ao mesmo tempo, analisar os lugares e as relações.

Todavia, nesse sistema de relações que é o espaço haveria, ainda, uma quinta dimensão, isto é, o cotidiano (Santos, 1996a, 1996c), que hoje se torna espesso pela multiplicidade de eventos que o atingem e que se fundem com os eventos nascidos no próprio lugar. $\bigcirc$ cotidiano só é possível no espaço contínuo que é o lugar. É "no decorrer de suas atividades cotidianas", escreve Giddens (1987, p. 113), que "os agentes reencontram-se nos contextos de interação precisa nos quais estão fisicamente em copresença".

Entretanto essas relações globais, nacionais e locais, constitutivas do lugar, são realizadas a partir da materialidade, que se desenvolve como uma condição para a ação, ora um limite, ora uma oportunidade (Santos, 1996a). Por isso, podemos dizer que o cotidiano compreende ambas as realidades, a material e a imaterial (Santos, 1996c), isto é, um tecido de objetos e ações de significativa complexidade nos dias de hoje. Dir-se-ia, portanto, que o cotidiano tem um conteúdo geográfico (Santos, 1996a).

1 "O espaço banal é o espaço de todos os indivíduos independentemente de todas [as] suas qualidades, o espaço de todas as empresas independentemente da sua força e o espaço de todas as instituições independentemente do seu poder normativo" (Santos, 1996b, p. 29). 
Tais premissas seriam um partido de método fundamental para discutir a relação entre finanças, consumo e cidadania porque permitem pensar o tempo próprio do lugar, que não é alheio aos embates dos eventos da globalização, mas que está longe de tornar-se homogêneo, como muitos anunciaram.

Nesse contexto, hoje enfrentamos, pelo menos, duas situações. De um lado, aceleram-se os fluxos e as trocas, materiais e imateriais e, de outro, multiplicam-se os lugares e agentes que participam de intercâmbios e conexões. $\bigcirc$ resultado é a produção, no lugar, de um acontecer espesso e inter-relacionado, fonte da percepção da simultaneidade e da universalidade. Explicando que a complexidade é hoje uma característica dos lugares, Maria Adélia de Souza (2006, p. 176) assevera que está "intimamente relacionada com uma nova percepção do tempo, na qual a presença e a coexistência se adaptam às novas, sucessivas e aceleradas ordens do mundo". Aquilo que o historiador Chesneaux (1976) reconhecia como a universalização dos mecanismos da história nos alerta para a profusão de objetos, ações e normas nos lugares que constituem o "cotidiano enriquecido", uma espécie de quinta dimensão do espaço banal. E acrescenta:

Como trabalhar a dimensão espacial do cotidiano e o cotidiano como quinta dimensão do espaço? Tudo isto tem que ver com a questão da cidadania, com a questão do espaço do cidadão, com a questão do espaço banal. $\bigcirc$ cotidiano é marcado, sobretudo nas cidades, com aquilo que Sartre chamou de efeito de residência. Esse cotidiano é delimitado pelo espaço contínuo e não por um espaço de pontos, ou de fluxos. É no espaço contínuo, onde todos os tipos de homens, todos os tipos de empresas, todos os tipos de instituições trabalham juntos, funcionam juntos e juntos estruturam a vida da comunidade e o espaço ao mesmo tempo. É o que estou chamando de horizontalidade e se completa com as verticalidades formadas por pontos discretos povoados por agentes hegemônicos desinteressados da vizinhança, despreocupados da copresença. Esse espaço contínuo, que é quadro de ação e que é limite à ação; esse espaço contínuo é o quadro de um funcionamento harmônico de tantos desiguais - ainda que não seja um funcionamento harmonioso (Santos, 1996c, p. 11).

Portanto, lugar e cotidiano se fundem e se confundem. Nesse processo, o lugar torna-se a referência pragmática do mundo, hoje atravessado pela força da finança que, no entanto, se defronta com a ação comunicativa (Santos, 1996a). Em outras palavras, a pergunta é como as pessoas produzem a partir das novas condições impostas pelas finanças, rearranjando suas formas de trabalhar ao sabor de uma informação fragmentária, porém ressignificada na copresença com agentes igualmente vulneráveis. As pessoas produzem com as finanças e apesar das finanças. A densidade comunicacional nutre-se da densidade informacional e, sobretudo, opõe-se a ela. ${ }^{2}$

2 "A densidade informacional nos indica o grau de exterioridade do lugar e a realização de sua propensão a entrar em relação com outros lugares, privilegiando setores e atores. A informação unívoca, obediente às regras de um ator hegemônico, introduz no espaço uma intervenção vertical, que geralmente ignora o seu entorno, pondo-se ao serviço de quem tem os bastões de comando". A densidade comunicacional nasce do "cotidiano partilhado", "do tempo conflitual da copresença", do espaço banal que "é criador da interdependência obrigatória e da solidariedade, geradas pelas situações cara a cara" (Santos, 1996a, p. 205). "As relações técnicas e informacionais podem ser indiferentes ao meio social ambiente. As relações comunicacionais são, ao contrário, uma resultante desse meio social ambiente" (Santos, 1996a, p. 206). 
Não buscamos entender o lugar unicamente a partir dele próprio, mas compreender que, malgrado a força das redes financeiras, o lugar tem uma potencialidade explicativa para a geografia e as demais ciências sociais que advém de sua indissociabilidade com o cotidiano. Eis a quinta dimensão que, todavia, não poderá ser entendida sem compreender as totalidades nas quais dinamicamente se insere.

No período atual amplia-se a rede de transações, aquilo que Cohen (2014, p. 18) entende como uma "argamassa" feita de "trocas mútuas entre agentes autônomos que fora isso podem ter pouco ou nada em comum e que podem até estar situados em locais totalmente diferentes". A financeirização é, portanto, uma manifestação empírica da globalização, talvez a mais evidente hoje, que autorizou a falar de capitalismo financeiro, de momento financeiro do modo de produção, de mundialização financeira. Como afirma Mónica Arroyo (2006, p. 181), "a uma base material adequada para aumentar a fluidez territorial, soma-se uma base normativa que facilita a porosidade do território a partir de regulações flexíveis". Entretanto, essa financeirização é uma tendência histórica que, embora obedeça a princípios organizacionais de lógica planetária, se realiza nos lugares porque sua existência é cotidiana. É ali, no lugar onde constatamos o aumento da densidade dos nexos financeiros, as possibilidades e os limites oferecidos pelo crédito e o respectivo aumento dos consumos. Mas é também no lugar onde percebemos a subordinação do trabalho a uma divisão internacional do trabalho hegemônica, a cidadania mutilada pelo exercício incompleto dos direitos, em definitivo, a presença dominante do mercado e a presença incompleta ou subordinada do Estado. Mas, o cotidiano tampouco existe sem o Estado.

\section{Financeirização e circuitos da economia urbana}

Essa quinta dimensão do espaço banal é um híbrido por excelência porque produzido pelas forças verticais e pelas existências horizontais. No que o cotidiano tem de vertical, como a chegada de um crédito e de um consumo cientificamente produzidos e sua condição de locus da produção de um acontecer hierárquico, revela a racionalização do espaço banal. Aqui as palavras de Simmel (2001), quando afirma que o dinheiro torna o mundo moderno um enorme problema aritmético, ganham novo significado. E, ainda mais, nos dias de hoje o mundo parecer ter se tornado um enorme problema algorítmico, cuja solução cria novas quantidades e qualidades financeiras para a vida cotidiana.

Naquilo que o cotidiano tem de horizontal, isto é, a realização de um consumo e de uma produção crescentemente dominados pelo acontecer hierárquico e os comandos da técnica, da informação e da finança deformados no encontro de múltiplas formas menos capitalizadas de produzir e consumir, revela o reino da pluralidade de aconteceres. Vistos na sua existência sistêmica, tais aconteceres podem ser analisados como circuitos da economia urbana (Santos, 1975; Silveira, 2009). ${ }^{3}$

Em certos pontos do planeta, observamos uma nova tecnologia, novas formas de organização - entre as quais os bancos de dados, a publicidade e seu corolário, aquilo que Gaudin (1999) denominava desinformação - e um capital que se mimetiza e hibridiza e nos confunde,

3 A cidade é um grande meio construído e um grande mercado, e pode ser analisada a partir dos diversos circuitos de produção e consumo que nela se desenvolvem. Quando as atividades são realizadas com altos graus de capital, tecnologia e organização, podemos reconhecer um circuito superior, contendo também uma porção marginal. Quando os graus são baixos, é do circuito inferior que falamos. Ambos os circuitos estão interligados pela oferta e pela demanda, sendo resultados das modernizações capitalistas. 
pois já não sabemos diferenciar o que é capital comercial do que é capital financeiro. Esses renovados fatores de produção participam na elaboração de uma ideia de consumo e da sua realização, aí incluído sobretudo o consumo de dinheiro e de instrumentos financeiros por meio da banalização das finanças. Embora Polanyi (2003) alertasse para o fato de que o trabalho, a terra e o dinheiro são mercadorias fictícias porque não são produzidas para a venda, também reconhecia que tais elementos são comprados e vendidos no mercado com a ajuda dessa ficção. No caso do dinheiro, afirmava "por regra geral não é produzido, porém surge a partir do mecanismo da banca ou das finanças estatais" (Polanyi, 2003, p. 123). É o caso dos instrumentos financeiros derivados que são as pedras basais do complexo edifício da intermediação financeira. Dowbor (1998, p. 242) compara essa intermediação com uma espécie de pedágio:

setor de intermediação financeira é caracterizado por uma extrema centralização, agravada recentemente com a introdução de novas tecnologias. E como todos, na economia moderna, precisam passar por este mecanismo, tornou-se um instrumento ideal de cobrança de pedágio sobre a economia em geral.

Ainda mais os agentes do circuito inferior, cujo problema é a liquidez, acabam pagando mais caro pelos mesmos bens e serviços, pois têm acesso a instrumentos financeiros com taxas mais altas, como foi pesquisado por Vannuchi $(2009)^{4}$ e discutido por Dowbor (1998). ${ }^{5}$

Malgrado sua segmentação, o crédito tende a banalizar-se já que, com Lazzarato (2013) podemos afirmar que se multiplica a produção contemporânea de devedores graças à automação do crédito que nos faz manter, sem sabê-lo, uma relação cotidiana com a economia da dívida. $\bigcirc$ autor é ainda mais enfático ao escrever sobre o momento atual:

Não há mais do que uma classe, reconstituída em torno às finanças, ao poder da moeda de crédito e ao dinheiro como capital [...] a relação credor/devedor introduz uma forte descontinuidade na história do capitalismo. Por primeira vez desde que existe, não é a relação capital/trabalho a que está no centro da vida econômica, social e política (Lazzarato, 2015, p. 13-14).

De tal modo, a banalidade do crédito e do consumo resulta desses fluxos e intercâmbios financeiros, contribuindo para criar a espessura do espaço e revelar a racionalidade do circuito superior. Mais do que nunca antes e a partir da ação técnica e da ação formal, os atores do circuito superior dominam o circuito inferior negando ou cooptando as racionalidades dos seus agentes, incluída a ação simbólica. ${ }^{6}$ Aqui cabe mencionar a publicidade que, orientada aos aposentados, por vezes os únicos membros da família com uma renda estável, cria uma demanda específica. Elaborada a partir de fundamentos científicos, a publicidade que encarna a força da

4 Vannuchi (2009) analisou o custo de um mesmo produto pago em 12 parcelas, segundo o instrumento financeiro utilizado (cartão de crédito, cartão da loja e crediário) em três grandes redes comerciais na cidade de São Paulo (Magazine Luiza, Ponto Frio e Pernambucanas). O crediário, forma mais utilizada pelos mais pobres, aumentava mais de $65 \%$ o valor de uma geladeira, se comparado com o valor pago à vista ou em parcelas sem juros com cartão de crédito.

5 Nas palavras do autor, "o pobre termina comprando os produtos a preços incomparavelmente superiores aos que pagam os ricos que podem pagar à vista, reforçando a concentração de renda e tornando o imposto financeiro regressivo" (Dowbor, 1998, p. 240).

6 "O agir técnico leva a interações formalmente requeridas pela técnica. $\bigcirc$ agir formal supõe obediência aos formalismos jurídicos, econômicos e científicos". O agir simbólico "não é regulado pelo cálculo e compreende formas afetivas, emotivas, rituais, determinadas por modelos gerais de significação e de representação" (Santos, 1996a, p. 66). 
ação técnica e formal e que impele camadas da população a tomarem créditos desburocratizados torna-se um elemento analítico de primeira importância. Não podemos esquecer que se as grandes empresas têm a capacidade de criar demandas por meio da publicidade e do crédito desburocratizado, também se orientam a fazer das verdadeiras necessidades, como o consumo de alimentos básicos, um mercado próprio. É o que acontece com a produção e a distribuição por meio das grandes redes em detrimento das pequenas lojas.

Desse modo, a "vida a crédito" implica a incorporação do hábito de viver com dívida e sem poupança (Bauman, 2007, p. 111), participando da "economia do engano" (Bauman, 2007, p. 72). Identificando tais processos, Bauman (2007, p. 136) cunhou a expressão homo consumens, mas alertando sobre a força ideológica e material do consumo e sobre os mandamentos do mercado no Brasil, Santos (1987, p. 41) já havia escrito: "onde não há o cidadão, há o consumidor mais-que-perfeito".

Na engrenagem do consumo, a taxa de juros desponta, no entendimento de Castaingts Teillery (2002), como uma forma de manipulação do tempo a partir de dois mecanismos: o cálculo do que o dinheiro valerá no futuro e a possibilidade de adiar os problemas atuais. Assevera o economista mexicano:

Agora a dimensão da temporalidade é determinada em função da taxa de juros. ○ cálculo do valor presente do dinheiro, que é o elemento central em todo o processo de decisões, conduz a que, na medida em que cresce a taxa de juros, a dimensão do tempo se encurta e ao contrário cresce quando se reduz a taxa de juros (Castaingts Teillery, 2002, p. 183).

Mas a falta de dinheiro e, depois, o empréstimo e a dívida fazem redescobrir a escassez menos no espaço de fluxos e mais nos lares e nos corpos ou, em outras palavras, na quinta dimensão do espaço banal, na qual o circuito inferior é um protagonista fundamental.

Dir-se-ia que no lugar, híbrido de verticalidades e horizontalidades, confrontam-se dois sistemas de ações: de um lado, aquilo que, já na década de 1970, Baudrillard (2011, p. 81) denominou "consumatividade" e, de outro, um fenômeno identificado por Zelizer (2011) como "marcado do dinheiro". Entendida como modo estrutural da produtividade, a consumatividade se refere ao processo pelo qual o desejo vai sendo abstraído e dividido em necessidades para fazê-lo homogêneo aos meios de satisfação tais como produtos, imagens e objetos-signos e, assim, multiplicar o consumo (Baudrillard, 2011).

Já o marcado do dinheiro, explica a socióloga Zelizer (2011), é a diferenciação e classificação do dinheiro com o propósito de limitar os usos ou, em outras palavras, a construção de diferentes formas de dinheiro. Na ação cotidiana, os pobres reservam uma parcela do dinheiro para alimentação, outra para o aluguel e outras para o resto das suas despesas essenciais. Para a autora (Zelizer, 2011, p. 37) "o marcado de dinheiro informal é um fenômeno tão poderoso quanto a criação oficial de moedas de curso legal" e, nesse processo de limitação dos usos do dinheiro, as pessoas "criam seu próprio espectro em lugar daquele que lhes é apresentado pelos governos e bancos" (Zelizer, 2011, p. 247).

Há aí uma permanente tensão, que parece mais forte nas áreas mais densas do território, entre a consumatividade e o marcado do dinheiro, entre o apelo ao consumo e a consciência das camadas mais pobres da sociedade de que o dinheiro é finito. Podemos reconhecer então o 
papel do crédito, crescente graças à racionalização da sociedade, da economia e do espaço, que tende a diminuir a fricção entre o desejo de consumo e as limitações do marcado do dinheiro nos orçamentos familiares.

Causa e consequência da financeirização do cotidiano, os pontos de drenagem proliferam nas cidades. Ora obtidos das atividades do circuito inferior, tantas vezes a partir das "economias dos centavos" na expressão cunhada por Marina Montenegro (2014, p. 222) para referir-se ao valor que as moedas assumem nos bairros pobres e populosos das grandes cidades brasileiras, ora advindos dos programas de transferência direta de renda como o programa "bolsa-familia", os pequenos excedentes são drenados a partir de pontos do circuito superior. Bancos, grandes redes comerciais que inclusive emitem cartões e demais instituições e empresas que fornecem crédito pessoal e crédito consignado, entre tantos instrumentos financeiros, se instalam nos centros históricos, nas novas centralidades, nas estações de metrô e ônibus, nas periferias e nas favelas.

No bairro da Penha, na Zona Leste de São Paulo, a financeira e banco Daycoval fornece crédito pessoal com juros anuais de 932,93\% e, no bairro do Capão Redondo, a Crefisa oferece crédito pessoal para "quem tem o nome sujo na praça" com juros anuais de 751,68\%. Manifestações empíricas da aceleração contemporânea, essas taxas leoninas parecem revelar uma "rede de pagamentos", própria do espaço monetário a que se referia Perroux (Cohen, 2014, p. 33). Nesse último bairro, pequenas lojas de móveis, eletrodomésticos e colchões oferecem vendas a crédito que, no entanto, não é fornecido por elas mas pela Losango, financeira do banco HSBC, adquirido no Brasil pelo Bradesco.

É também conhecida a recente estratégia dos supermercados e hipermercados de instalar filiais nas favelas ou na vizinhança destas. Donos de pequenas mercearias da favela Heliópolis compram agora no supermercado Atacadão localizado nas imediações, embora lamonti (2009) já havia observado que as pequenas quitandas se abasteciam nas redes atacadistas Makro e Sam's, nas proximidades do bairro. É frequente a redefinição da forma de pagamento dos clientes por parte do supermercado como, por exemplo, o encurtamento dos prazos ou o aumento dos juros, mas, quando isso acontece, essas pequenas lojas ficam mais vulneráveis.

Por outra parte, em algumas cidades argentinas pudemos constatar a persistência de agiotas informais que fornecem empréstimos para a compra de eletrodomésticos e, sobretudo, de motos, cujo mercado é crescente em aglomerações médias onde o transporte público é deficiente. Nessas situações, os tomadores do empréstimo devem reembolsar o agiota em prestações dia sim, dia não. Numa dinâmica semelhante, em muitas cidades colombianas os agiotas emprestam dinheiro no sistema denominado "gota a gota" ou "pagadiario", que implica o empréstimo de quantias pequenas (em torno de 20 dólares), cuja devolução é diária (dois dólares diários até completar 24 dólares). Não existe, entretanto, um consenso sobre a ilegalidade dessa prática que avançou nas camadas médias com empréstimos de mil dólares. ${ }^{7}$ Um tipo de empréstimo que permite ao dinheiro gerar dinheiro.

7 Essa modalidade, que começou como estritamente financeira, hoje está relacionada com o crime e com as forças paramilitares. Quando a pessoa não paga, tomam tudo o que ela tem ou o conflito é resolvido por meio da força. É um exemplo da violência do dinheiro que se espalha nas nossas cidades (Serna, 2015). 
Mas, como explica Ana Clara Torres Ribeiro (2005, p. 418), os que precisam sobreviver a cada dia "reduzem, espontaneamente, impactos da financeirização da vida urbana, mediante uma infinidade de gestos-fio que renovam as trocas banais, e também surpreendentes, no cotidiano e nos lugares". Para a autora, um gesto-fio é a expressão da solidariedade e da compreensão na copresença. Daí que possamos reconhecer um gesto-fio no empréstimo do nome para obter um crédito. Para quem carece de capital, essa ação revela que "dos gestos-fio impensados podem advir descobertas radicalmente novas e vínculos imprevisíveis, o que também é necessário à tessitura do social, especialmente num período caracterizado pelo esgarçamento de relações sociais" (Ribeiro, 2005, p. 421). O reconhecimento do outro, que não busca impor normas e que precisa resolver o sustento do dia, leva a um diálogo permanente e fortalece a densidade comunicacional.

A financeirização da vida e do território deixa transparecer uma dupla tendência, isto é, a ubiquidade da finança e do consumo tanto nas periferias metropolitanas como na rede urbana. No núcleo da metrópole, delineado pelos novos centros empresariais, são elaboradas ou retransmitidas ao resto da cidade e do território as variáveis determinantes que explicam a produção da ideia de consumo e sua realização. É ali que encontra as condições para sua realização no âmbito metropolitano um circuito superior que cresce por autopropulsão. Bancos, instituições financeiras, consultoras, sedes das grandes firmas comerciais, financeiras e industriais, grandes agências de publicidade, firmas de alta tecnologia, fundos de investimento, grandes shopping centers são os agentes hegemônicos que exercem a ação política e boa parte da ação técnica que produz a financeirização, embora isto se dê de forma mais ou menos incompleta nas nossas formações socioespaciais. Nas palavras de Adriana Bernardes Silva (2012, p. 6):

A difusão do consumo apoiado no trabalho e na técnica da pesquisa de mercado, através da informação, se constitui em fator determinante para a modernização do território brasileiro. As agencias de pesquisa de mercado preparam indiretamente o território nacional para receber as novas formas e feições racionais necessárias à expansão do capitalismo e de sua lógica.

Por outra parte, nas periferias as funções bancárias parecem diluir-se no tecido urbano por meio dos correspondentes bancários, estudados por Leila Dias e Maria Helena Lenzi (2009) e Fabio Betioli Contel (2011) no Brasil, das empresas advindas da terceirização bancária na Argentina (Creuz, 2015), das instituições financeiras de crédito desburocratizado (Parserisas, 2012) e da crescente utilização de posnet e outros dispositivos como a "moderninha" nas feiras e mercados de rua, mas também nas pequenas lojas (Montenegro, 2014; Silveira, 2016). Mais recentemente, o dinheiro eletrônico assume novas formas e pode ser transferido pelos telefones celulares, permitindo que a financeirização avance inclusive sobre as camadas da população que carecem de conta bancária. ${ }^{8}$ Trata-se de uma modernização do próprio circuito inferior que implica um aumento dos seus custos fixos e contribui para criar o que Contel (2011, p. 280) denominou "hipercapilaridade do acesso ao crédito".

8 No Quênia, a partir de 2007, o programa M-Pesa foi implementado por uma firma controlada pela Vodafone e com participação do Estado. Em 2013, já eram mais de 18 milhões de usuários que utilizavam o sistema para depósitos, saques e envio de remessas. Em 2012, foi criada a M-Shwari, uma plataforma bancária vinculada à M-Pesa que permite fazer aplicações e receber créditos. Esse país se tornou um laboratório das políticas consideradas de inclusão financeira (Bekerman, 2017). 
Por fim, visto a partir da rede urbana, o fenômeno da financeirização revela diversos retratos no território, sendo um dos mais significativos a expansão das grandes empresas comerciais e financeiras nas cidades médias. Graças à publicidade e ao crédito, mas também à existência de uma demanda das novas classes médias e dos quadros profissionais que desenvolvem atividades próprias de uma economia moderna, agentes de um circuito superior metropolitano ou mesmo externo invadem os mercados tradicionalmente pertencentes a um circuito superior regional. É o caso das grandes redes de supermercados, eletrodomésticos, bancos e financeiras que, amiúde, tomam o lugar dos estabelecimentos locais (Sposito, 2015; Di Nucci, 2015).

\section{Estado e cidadania}

Na discussão entre Estado e cidadania, dois problemas, entre tantos outros, poderiam ser reconhecidos. $\bigcirc$ primeiro é a falta de uma definição clara da ideia de cidadania e da compreensão dos alcances da financeirização. É, sem dúvida, um problema político, mas é também um problema epistemológico porque advém de uma visão setorial, por vezes economicista, que privilegia certas variáveis e parece ignorar outras que muito contribuiriam para a formulação do problema em termos territoriais e o encontro das respectivas soluções. Uma vertente é a aceitação da ideia de crescimento econômico como solução per se, uma premissa que atravessa os partidos políticos de signos bastante diferentes. $\bigcirc$ australiano Hamilton (2006, p. 24) sintetiza essa perspectiva ao escrever que em todos os partidos, incluídos os progressistas, "a resposta a quase qualquer problema é mais crescimento econômico". Não ignoramos a importância de tal processo macroeconômico, mas torna-se necessário discutir as bases da modernização que implica pois, quando sua natureza é seletiva, as consequências da desigualdade limitam significativamente o exercício da cidadania.

Outro ponto importante e vinculado ao anterior também tende a produzir o que Ribeiro (2011, p. 21) definiu como "consensos rápidos". Trata-se da convicção nas benesses dos consumos consumptivos. Assim, a expansão de tais consumos, sem atentar para os necessários consumos produtivos, é vista como um caminho do progresso social. No entanto, o que temos como corolário é a existência de mais de uma geração desprovida de patrimônio, seja este orientado para a produção ou para a reprodução da vida. Coexiste com essa realidade certa falta de análise ou de uma clara compreensão do papel do endividamento individual na base do crédito desburocratizado e caro e dos problemas sociais derivados, tais como a violência. Além disso, poderíamos mencionar a falta de regulação ou de aplicação de normas que impeçam a consolidação do crime organizado, que atravessa diversas formas de comércio e serviços, incluídos os financeiros. E, por fim, assinalamos a frequente ausência de uma correta interpretação e de políticas derivadas que permitam enfrentar a carência de bens e serviços universais, que está na raiz da pobreza estrutural mesmo num contexto de crescimento.

Entretanto esse não é o único problema que enfrentamos. Assinalamos, também, as contradições entre políticas advindas dos diferentes níveis do Estado. De um lado constatamos a existência de políticas públicas orientadas a fortalecer os agentes do circuito superior, sobretudo aqueles vinculados às finanças e à produção e distribuição em grande escala e, de outro, 
observamos a formulação de políticas de apoio à produção para as pequenas empresas. Esse apoio coexiste, não raro, com ações de fiscalização de pequenos agentes em função da sua localização, da tributação e da sanidade, nem sempre replicadas entre os verdadeiros motores das ações ilegais, tantas vezes pertencentes aos níveis mais capitalizados da economia.

Nesse contexto reconhecemos a necessidade de liquidez e o aumento dos consumos mercantis pela impossibilidade de satisfazer as demandas como consumos sociais. Portanto, a finança reforça sua condição dominante e indispensável porque possibilita e multiplica as formas desse consumo mercantil. Havendo constatado o grave problema da desigualdade, frequentemente acelerado pelos altos custos do dinheiro cobrados dos mais pobres, podemos ver mais nitidamente suas consequências sobre a mutilação dos direitos. Mas a esse argumento cívico pode-se acrescentar um argumento econômico. $\bigcirc$ que acontece com as formas de produção e consumo que poderiam perdurar ou nascer se conseguíssemos afiançar o exercício da cidadania? É Rosanvallon (1995) que ilumina a questão ao sublinhar o direito à utilidade recíproca, uma vez que não é suficiente a solidariedade para vincular os membros de uma sociedade. Na opinião do autor é necessário resguardar o direito a sustentar-se pelo próprio trabalho, isto é, o direito de associar a renda ao reconhecimento da função social. Haveria, outrossim, a possibilidade de identificar e qualificar uma demanda, já existente na sociedade, cuja satisfação contribuiria a abandonar a noção de cidadania como forma vazia do discurso e preenchê-la como um conteúdo da existência. Estamos fazendo alusão aqui a um conjunto de infraestruturas, dispositivos e serviços pessoais qualificados que permitiriam uma vida melhor, como por exemplo, soluções técnicas e organizacionais para necessidades advindas das limitações de algumas pessoas para permanecer ou circular nas nossas cidades. E, nesse processo de satisfação de tais demandas invisíveis ou eclipsadas, não poucos empregos poderiam ser criados.

Ao mesmo tempo, torna-se fundamental fortalecer os consumos sociais e não apenas os mercantis, já que existem bens e serviços que são de interesse comum, representativos de direitos tradicionalmente chamados naturais, que deveriam ser reconhecidos como direitos legítimos para todos. Aqui a reflexão de Bobbio (2010) permite iluminar a questão quando explica que a única forma de fortalecer o fluxo ascendente do poder é ampliar a democracia política numa democracia social, uma vez que os direitos políticos sem justiça distributiva não levam a uma democracia social.

\section{Algumas palavras finais}

Na discussão que envolve o lugar e o cotidiano, as finanças e a cidadania, há, certamente, mais perguntas que respostas. Contudo, o debate amiúde está imbuído de uma visão unidimensional e distorcida do homem contemporâneo. Referimo-nos à convicção de que a conquista da cidadania se dará pela ampliação dos consumos mercantis. Mesmo no âmago dessa ideia parece haver uma tensão entre uma tendência à homogeneização da sociedade e do território, por vezes um objetivo da política, e uma tendência à segmentação pela desigualdade de renda, uma realização do mercado. $\bigcirc$ crédito e o respectivo endividamento dos mais pobres é o instrumento usado para diluir tal tensão. Utilizando de um modo mais abrangente a imagem de Bobbio (2010, p. 62) quando explica os fluxos ascendentes e descendentes que estruturam o Estado moderno, poderíamos dizer que hoje, por meio do crédito desburocratiza- 
do, os bancos e as financeiras impõem um fluxo descendente de máxima burocratização. Essa situação parece ser ainda mais grave no momento em que os governos abandonam algumas responsabilidades importantes:

Governar não implica apenas resolver os problemas de organização, distribuir de maneira racional os recursos, planejar uma ação no tempo. Governar significa em primeiro lugar fazer inteligível o mundo, fornecer instrumentos de análise e de interpretação que permitam aos cidadãos entender e atuar de maneira eficaz. Há aí uma dimensão fundamentalmente cognitiva do político que deve ser salientada [...] (Rosanvallon, 2007, p. 295).

Refletindo sobre a necessidade de que a educação forme indivíduos fortes, Santos (1998, p. 16) escreveu que "o indivíduo forte é aquele que, diante do futuro, é capaz de escolher por si mesmo", e acrescentou que "não basta criar cidadãos formais, se também não se criam indivíduos fortes". E, no âmago dessa reflexão, o consumismo desponta, na opinião do autor, como um fundamentalismo porque leva à redução da vontade de ser um indivíduo forte.

Defronte a essas questões, há o risco de um grande esquecimento. Mais do que o consumo, considerado isoladamente, parece indispensável entender o trabalho como forma de conquista de uma cidadania mais sólida e duradoura. Um empecilho se deve ao fato de o direito à produção se limitar pela renovação dos meios de produção e pelos custos dos fatores de produção. A contrapartida é a possibilidade de consumir mais enquanto cada vez são menos os que podem produzir com esses parâmetros.

Entretanto, sendo o consumo uma variável dominante do período, não é mais possível insistir em antinomias. A pergunta é, talvez, quem produz o que é consumido, atentando-se para o papel dos pequenos agentes. Desse modo, e sem o prejuízo da crítica aos consumismos de diversas naturezas, o consumo poderia ser visto como motor da vida econômica porque descortina novas possibilidades para as demais divisões territoriais do trabalho.

No lugar, o cotidiano resulta da cooperação e do conflito. Desse modo, as forças de organização, verticalmente construídas, buscam instalar uma visão sobre as benesses da fluidez, do dinheiro e do trabalho subordinado a uma estrutura maior. Mas também existem forças espontâneas, nascidas na copresença e na contiguidade, que permitem vislumbrar, com maior ou menor nitidez, as possibilidades do período e as adversidades do que Santos (2000) denominou dinheiro em estado puro.

Por isso, e como o futuro nos reserva novas possibilidades e combinações, as palavras de Marc Augé (2012, p. 62) são esclarecedoras quando lembra que "a contemporaneidade não se reduz apenas à atualidade". Daí que tenhamos na nossa frente complexos desafios não apenas políticos, mas também teóricos. Nosso trabalho é continuar elaborando uma epistemologia interna, com sistemas de conceitos aptos para enfrentar essa contemporaneidade que inclui o futuro. Tudo isso deverá ser construído sem deixar de lado o encontro dos princípios de solidariedade que nos afastem da barbárie, evitando que o dinheiro seja o centro da civilização e elaborando teorias numa perspectiva humana, humanista, socializante. 


\section{Referências}

ARROYO, M. A vulnerabilidade dos territórios nacionais latino-americanos: o papel das finanças. In: LEMOS, A. I. G.; SILVEIRA, M. L.; ARROYO, M. Questões territoriais na América Latina. Buenos Aires: Clacso/São Paulo: Universidade de São Paulo, 2006. p. 177-190.

AUGÉ, M. Futuro. Buenos Aires: Adriana Hidalgo, 2012.

BAUDRILLARD, J. Crítica de la economía política del signo. 12. reimp. Ciudad de México: Siglo XXI, 2011.

BAUMAN, Z. Vida de consumo. Buenos Aires: Fondo de Cultura Económica, 2007.

BEKERMAN, M. El desafío de incluir con servicios financieros. Diario La Nación, Buenos Aires, mar. 2017.

BERNARDES SILVA, A. M. Círculos de informações, urbanização e usos do território brasileiro. Revista da ANPEGE, Dourados, v. 8, n. 10, p. 3-15, 2012.

BOBBIO, N. El futuro de la democracia. 3. ed. Ciudad de México: Fondo de Cultura Económica, 2010.

CASTAINGTS TEILLERY, J. Simbolismos del dinero. Antropología y economía: una encrucijada. Barcelona: Anthropos, 2002.

CHESNEAUX, J. Du passé faisons table rase? A propos de 1'histoire et des historiens. Paris: Maspero, 1976.

COHEN, B. J. A geografia do dinheiro. São Paulo: Ed. Unesp, 2014.

CONTEL, F. B. Território e Finanças: técnicas, normas e topologías bancárias no Brasil. São Paulo: Annablume, 2011.

CREUZ, V. Los ardiles del capital bancario. Manifestaciones en las ciudades de Buenos Aires y São Paulo. In: VIDAL-KOPPMANN, S. (Org.). Metrópolis en Mutación. Buenos Aires: Café de las Ciudades, 2015. p. 497-520. v. 1.

DIAS, L. C.; LENZI, M. H. Reorganização espacial de redes bancárias no Brasil: processos adaptativos e inovadores. Caderno CRH, Salvador, v. 22, n. 55, p. 97-117, abr. 2009.

DI NUCCI, J. I. Concentración y uso corporativo del territorio en Argentina: la lógica territorial de Carrefour. Cuadernos Geográficos, Tandil, v. 54, n. 1, p. 186-208, 2015.

DOWBOR, L. A reprodução social: propostas para uma gestão descentralizada. Petrópolis: Vozes, 1998.

GAUDIN, T. Economia cognitiva. São Paulo: Beca, 1999.

GIDDENS, A. La constitution de la société: élements de la théorie de la structuration. Paris: Presses Universitaires de France, 1987.

HAMILTON, C. El fetiche del crecimiento. Pamplona: Lactoli, 2006. 
IAMONTI, V. Z. O circuito inferior na favela de Heliópolis. Trabalho de Graduação (Geografia) - Faculdade de Filosofia, Letras e Ciências Humanas, Universidade de São Paulo, São Paulo, 2009.

LAZZARATO, M. Gobernar a través de la deuda: tecnologías de poder del capitalismo neoliberal. Buenos Aires: Amorrortu, 2015.

La fábrica del hombre endeudado: ensayo sobre la condición neoliberal. Buenos Aires: Amorrortu, 2013.

MONTENEGRO, M. R. Globalização, trabalho e pobreza nas metrópoles brasileiras. São Paulo: Annablume/Fapesp, 2014.

PARSERISAS, D. D. Circuitos de la economía urbana y modernización del sistema financiero de crédito en Olavarría. Mundo Urbano, n. 38, mar. 2012.

POLANYI, K. La gran transformación: los orígenes políticos y económicos de nuestro tiempo. 2. ed. Ciudad de México: Fondo de Cultura Económica, 2003.

RIBEIRO, A. C. T. Territórios da sociedade: por uma cartografia da ação. In: SILVA, C. A. (Ed.). Território e ação social: sentidos da apropriação urbana. Rio de Janeiro: Lamparina, 2011. p. 19-34.

Sociabilidade, hoje: leitura da experiência urbana. Caderno CRH, Salvador, v. 18, n. 45, p. 411-422, set./dez. 2005.

ROSANVALLON, P. La contrademocracia: la política en la era de la desconfianza. Buenos Aires: Manantial, 2007.

La nueva cuestión social: repensar el Estado providencia. Buenos Aires: Manantial, 1995.

RUSSELL, B. El conocimiento humano. Barcelona: Orbis, 1983. (Colección Historia del Pensamiento).

SANTOS, M. Por uma outra globalização: do pensamento único à consciência universal. Rio de Janeiro: Record, 2000.

A técnica em nossos dias - a instrução e a educação. ABMES, Brasilia, v. 1, n. 1, p. 7-27, 1998.

A natureza do espaço: técnica e tempo, razão e emoção. São Paulo: Hucitec, 1996a.

El espacio banal, una epistemología de la existencia. Solemne Investidura Doctor Honoris Causa - Universitat de Barcelona, nov. 1996b. p. 25-31.

. Por uma Geografia Cidadã: por uma epistemologia da existência. Boletim Gaúcho de Geografia, Porto Alegre, n. 21, p. 7-14, 1996c.

O espaço do cidadão. São Paulo: Nobel, 1987.

Por uma Geografia Nova: da crítica da Geografia a uma Geografia Crítica. São Paulo: Hucitec, 1986. 
L'Espace Partagé: les deux circuits de l'économie urbaine des pays sous-développés. Paris: Librairies Techniques, 1975.

SERNA, J. F. El "gota a gota" que rebosa la taza. El Colombiano, 23 set. 2015. Disponível em: http://www.elcolombiano.com/antioquia/seguridad/el-gota-a-gota-que-rebosa-la-taza-CF2755532. Acesso em: 24 ago. 2017.

SILVA, A. C. De quem é o pedaço? Espaço e Cultura. São Paulo: Hucitec, 1986.

SILVEIRA, M. L. São Paulo: entre la regencia del territorio y los mercados metropolitanos. In: SILVEIRA, M. L. (Coord.). Circuitos de la economía urbana: ensayos sobre Buenos Aires y São Paulo. Buenos Aires: Café de las Ciudades, 2016. p. 217-258.

. Finanças, consumo e circuitos da economia urbana na cidade de São Paulo. Caderno CRH, Salvador, v. 22, n. 55, p. 65-76, 2009.

SIMMEL, G. The philosophy of money. Londres: Routledge, 2001.

SOUZA, M. A. A. A geografia da solidariedade. GeoTextos, Salvador, v. 2, n. 2, p. 171-178, 2006.

SPOSITO, M. E. B. Metropolização do espaço: cidades médias, lógicas econômicas e consumo. In: FERREIRA, Á.; RUA, J.; MATTOS, R. C. (Org.). Desafios da metropolização do espaço. Rio de Janeiro: Consequência, 2015. p. 125-151.

VANNUCHI, L. V. B. Novos nexos na economia urbana da cidade de São Paulo: as grandes redes comerciais varejistas e suas interferências no circuito inferior. Trabalho de Graduação (Geografia) - Faculdade de Filosofia, Letras e Ciências Humanas, Universidade de São Paulo, São Paulo, 2009.

ZELIZER, V. A. El significado social del dinero. Buenos Aires: Fondo de Cultura Económica, 2011. 